\title{
DESVENDANDO O BOOK BUILDING EM OFERTAS DE AÇÕES ${ }^{1}$
}

\author{
Patrícia Ribeiro Romano - patricia_ribeiro_romano@ hotmail.com \\ Universidade Federal do Rio Grande do Norte - UFRN, Natal - RN, Brasil
}

ViniCIO DE SOUZA E AlMEIDA - almeida.vinicio@gmail.com

Universidade Federal do Rio Grande do Norte - UFRN, Natal - RN, Brasil

Na primavera de 2009, a Sopape, empresa do setor de prestação de serviço de abastecimento de água e de esgotamento sanitário, possuía como acionistas majoritários a família Bonaparte, que detinha 59\% de todas as ações com direito a voto, e a família Suassuna, que possuía 9,67\% das ações com direito a voto.

A família Suassuna estava passando por uma grave crise financeira e queria liquidar todas as suas ações na companhia da maneira mais rápida possível. Já os Bonapartes estavam dispostos apenas a vender uma pequena parte, para investir em outro empreendimento da família. O Sr. Carlos Eduardo Nicola, presidente da companhia, teve que aceitar as pressões por parte dos acionistas majoritários, iniciando o processo de oferta de ações subsequente (follow-on), também chamada addon. A abertura de capital (Initial Public Offering - IPO) da companhia foi realizada em 2006, quando a empresa arrecadou o montante de $\mathrm{R} \$ 813$ milhões, que foi utilizado principalmente em novas concessões de água e esgoto.

O mercado de capitais brasileiro viveu, no período entre 2004 e 2007, uma onda de ofertas públicas de ações, apoiada no bom momento da Bolsa de Valores de São Paulo (Bovespa, hoje BM\&FBovespa). O volume ofertado e a quantidade de ofertas públicas bateram recorde em 2007, aquecendo um mercado razoavelmente adormecido.

Alguns dos marcos para esse incremento foram a edição da Instrução CVM nº 400, a criação do Novo Mercado pela então Bovespa e a publicação do Código de Autorregulação da Associação Nacional de Bancos de Investimento (Anbid, hoje Anbima) para Ofertas Públicas de Distribuição e Aquisição de Valores Mobiliários. A Instrução CVM no 400, de 2003 (substituída pela Instrução CVM no 480, em 2009), representa um avanço normativo no que diz respeito a regras de transparência e padronização em ofertas públicas, provendo a base do ambiente regulatório no País para o tema. Os níveis diferenciados na BM\&FBovespa (entre eles, o Novo Mercado) e o Código da Anbima são a formalização do crescimento das políticas de autorregulação do mercado de capitais brasileiro.

\footnotetext{
${ }^{1}$ Os nomes da empresa e dos personagens são fictícios para preservar as fontes do caso real. 
No ano de 2007, o mercado acionário brasileiro viveu seu melhor momento desde o começo da onda em 2004, quando foram realizadas 76 ofertas de ações, tanto IPOs quanto follow-ons. O volume das ofertas de ações suplantou o volume das ofertas de debêntures, que passaram à primeira posição do volume negociado entre as categorias de ativos no mercado brasileiro, o que indica uma mudança de preferência de canais de captação de recursos pelas empresas brasileiras no período.

\section{Escolha dos bancos coordenadores de primeira linha}

A Sopape tinha relações muito próximas com o Banco Dic, que prestava assessoria financeira para grande parte das transações da empresa. A companhia das famílias Bonaparte e Suassuna usou o Banco Dic para consultar os bancos de investimento em mercado, tentando averiguar quem teria interesse e experiência para fazer a coordenação dessa oferta. Entretanto, o Banco Dic não enviou carta convite para nenhum dos bancos em mercado. $O$ gerente responsável pela área de investimentos no Banco Dic convidou o Banco Bono para coordenar a oferta de capitais da empresa, de maneira camarada, uma vez que já tinha trabalhado no Banco Bono. Porém, existia um problema: o Banco Bono não dispunha de estrutura suficiente para coordenar toda uma oferta de ações, tendo apenas uma razoável parte operacional.

Consequentemente, ele não conseguiria conduzir a oferta a investidores estrangeiros, o que é fundamental no Brasil. Em média, 70\% do volume ofertado em ações no mercado brasileiro é alocado para investidores estrangeiros. Assim, é preciso possuir uma base de relacionamentos no exterior, pelo menos uma na Europa ou nos Estados Unidos. Isso o Banco Bono não possuía, ou seja, não tinha essa estrutura lá fora.

Foi necessário, portanto, contratar outro intermediário financeiro que possuísse essa organização com posição internacional para realizar, efetivamente, a condução de todo o processo de vendas. Os dois bancos, Dic e Bono, reuniram-se para escolher um banco que fosse o líder de fato da oferta. Eles, de maneira conjunta, consultaram potenciais interessados nesse processo e foi feita uma carta convite para alguns deles. Nove responderam. Entre eles, o Country Bank ofertou a menor taxa de remuneração exigida, 2,39\%. Essa taxa foi considerada muito pequena quando comparada com a praticada no mercado brasileiro (ver Anexo 1).

A justificativa para o Country Bank ter feito esse tipo de oferta reside no fato de a liderança refletir diretamente na reputação do banco. O mercado está amplamente dominado pelo UBS e pelo Credit Suisse (CS), com coordenação de cerca de $70 \%$ das ofertas. O Country Bank utilizou essa taxa como uma estratégia para conseguir espaço no mercado. Com a oferta, ele subiria algumas posições nos rankings elaborados e divulgados pela Anbima, os quais pontuam melhor os bancos que mais coordenam ofertas, ofertam ações de maior volume e vendem mais.

O Banco Bono também queria aumentar a percepção sobre sua reputação, já que isso o ajudaria a conseguir mandatos para participar de consórcios de outras ofertas. Mas, como não tinha estrutura de vendas no mercado externo, contratou outro banco, no caso, o Country Bank, para conduzir o processo. Além desse obstáculo, o Bono teve outro entrave que impedia sua articulação no processo: não possuía uma autorização chamada Financial Holding Company (FHC).

A FHC é uma autorização concedida para entidades financeiras envolvidas em uma ampla gama de atividades bancárias relacionadas, criada pela Lei Gramm-Leach-Bliley, de 1999. A qualificação permite ao banco exercer suas funções em território norte-americano nas mesmas condições inerentes às instituições financeiras locais. Na prática, significa que poderia abrir ou relocalizar dependências, operar com residentes nos EUA, adquirir instituições bancárias e ampliar o 
escopo de atuação em mercado de capitais no país. O Federal Reserve System (FED) é o órgão responsável por credenciar e supervisionar a situação e as atividades das companhias financeiras. A FHC autoriza uma instituição financeira a atuar como intermediária no mercado norte-americano de emissões de títulos.

Mesmo que não tenha a FHC, o banco pode, ainda, negociar títulos com investidores estrangeiros ao abrigo da Regra 144A - dispositivo normativo norte-americano que regula colocações privadas nos EUA - e ao abrigo da Reg S - dispositivo norte-americano que regula colocações privadas fora dos EUA. No Brasil, a oferta está sendo feita ao abrigo da Instrução CVM 429/2006, que exige ampla publicidade de características da oferta e uniformidade da disseminação das informações, entre outros aspectos. A oferta para investidores estrangeiros - sob a Regra 144A ou sob a Reg S - não precisa passar pela Securities and Exchange Comission (SEC) com grandes exigências.

Sob a Regra 144A ou sob a Reg S, a oferta só pode ser destinada aos investidores qualificados como Qualified Institutional Buyers (QIBs). Para ser qualificada como QIB, a instituição tem que atender certos requisitos legais e, no mercado dos EUA, ter sob gestão pelo menos US\$ 100 milhões. Em tese, esses investidores são mais sofisticados e mais informados, necessitando de menor proteção por parte dos agentes públicos. Ao aderir a essas regras, a companhia emissora fica isenta da obrigatoriedade (e dos pesados custos) de adesão à Lei Sarbanes-Oxley (SOX), aplicável a todas as companhias que têm ações listadas no mercado norte-americano. Quando a oferta é feita pela Regra 144A ou pela Reg S, as ações ficam negociadas somente no mercado de origem da companhia. Não há exigência de entrega de documentos para a SEC, mas são requeridos alguns procedimentos relativamente simples: é preciso produzir um memorando de oferta, que é praticamente um prospecto traduzido, e assinar um contrato como o de distribuição, chamado de Placement Facilitation Agreement. O Anexo 3 apresenta mais detalhes sobre as normas para ofertas a investidores internacionais.

\section{Escolha dos bancos de segunda linha}

Depois da escolha dos bancos coordenadores, houve a necessidade, por parte da Sopape, de requerer a inclusão de coordenadores contratados, que são os chamados bancos de segunda linha. A escolha dos coordenadores contratados é mais desejada pelas emissoras, que querem criar demanda para ação, do que pelos bancos coordenadores, que não querem dividir sua remuneração. Porém, uma vez que a emissora se decidiu por ter coordenadores contratados em sua oferta, o banco líder auxilia na sua escolha. Os bancos coordenadores são considerados como de primeira linha e os coordenadores contratados, como de segunda linha. A classificação está intimamente ligada à posição das logomarcas dos bancos nos anúncios públicos das ofertas.

Na oferta da Sopape, o Banco Dic, o Banco Bono e o Country Bank participarão como coordenadores de primeira linha. Grande parte da remuneração dos bancos costuma ser reservada para o comissionamento pelas vendas das ações. Como o banco líder tem maior parcela das vendas, geralmente maior que $50 \%$ das ações ofertadas, fica também com boa parte da remuneração. Os demais bancos de primeira linha têm menores parcelas para alocar e, assim, remunerações reduzidas. Aos coordenadores contratados, são destinados lotes residuais para venda. Sua remuneração pode ser composta por partes fixas e por partes variáveis, a depender do quanto vendem. Esses componentes variáveis da remuneração e sob disputa entre coordenadores são conhecidos como jump ball. A divisão entre as proporções das partes fixas e partes variáveis nas remunerações dos bancos pelas 
vendas varia, mas geralmente fica em torno de $30 \%$ fixa e $70 \%$ variável (jump ball). Em algumas operações, o sistema pode ser de $100 \%$ de jump ball para os coordenadores contratados.

A Sopape queria contar com futuras designações de analistas de outros bancos para emitir relatórios sobre a companhia. Essas designações sempre acontecem quando um banco participa de uma oferta de ações, ainda que apenas como banco de segunda linha. Assim, os bancos coordenadores da oferta enviaram cartas convites para diversas entidades bancárias. O Banco Ômega e o Banco Santo responderam positivamente e aceitaram participar da oferta recebendo $\mathrm{R} \$ 550.000$ como parcela fixa e R $\$ 1.000$ como jump ball.

O processo de oferta de ações da Sopape foi conduzido pelo coordenador da oferta internacional, o Country Bank, pelo coordenador da oferta brasileira, o Banco Bono, pelo agente estruturador, o Banco Dic, e pelos bancos contratados, de segunda linha, o Banco Ômega e o Banco Santo.

\section{Principais características da empresa e do setor}

As atividades relacionadas ao setor de saneamento compreendem o abastecimento de água e o esgotamento sanitário. Modernamente, definem-se como saneamento ambiental de uma forma mais abrangente, além das anteriores, as ações voltadas à coleta e disposição de resíduos sólidos, controle de vetores, drenagem, recuperação de áreas ambientalmente degradadas, planejamento e gestão dos recursos hídricos, controle da poluição e educação sanitária.

A estrutura empresarial do setor de saneamento encontra-se, atualmente, organizada em 27 Companhias Estaduais de Saneamento Básico (CESBs). De acordo com dados do ano de 1996 (Secretaria de Políticas Urbanas do Ministério do Planejamento e Orçamento - MPO/Sepurb), essas companhias empregaram diretamente cerca de 100 mil pessoas e geraram, em conjunto, um faturamento da ordem de US\$ 6,25 bilhões. São responsáveis pelo abastecimento de água de $85 \%$ da população urbana e de $28 \%$ do esgotamento sanitário dessa mesma população, o que equivale, respectivamente, a uma população de cerca de 85 milhões de habitantes atendidos com água potável e 32 milhões de habitantes servidos por redes de esgotos sanitários.

Em reunião com os acionistas da Sopape, o presidente da companhia apresentou dados que davam conta de que os resultados operacionais e as condições financeiras da companhia são afetados diretamente pelas condições econômicas do País, especialmente por índices de inflação, taxas de juros, variações cambiais, políticas tributárias e de restrição ao endividamento público. Ademais, a demanda por serviços de abastecimento de água e esgotamento sanitário é afetada pelo desempenho da economia brasileira.

Os custos tendem a aumentar com a inflação brasileira, tendo em vista que os preços dos insumos que a empresa utiliza aumentam para refletir essa situação, o que pode afetar adversamente suas margens. A perspectiva atual em relação ao comportamento da inflação é de ligeira alta para os próximos anos. Além disso, seus resultados operacionais e condição financeira são afetados, ainda que moderadamente, pelas flutuações das taxas de juros e do câmbio, na medida em que parte de sua dívida está indexada a taxas de juros variáveis e à moeda estrangeira.

O setor de saneamento contribui para melhoria de condições de vida da população, por meio da infraestrutura e atendimento adequado em relação aos serviços; esse setor envolve forças ambientais que vão desde a captação e preservação dos recursos hídricos até a coleta e tratamento dos esgotos, evitando a poluição dos rios. A Sopape não possui concorrentes diretos na cidade onde atua. 
Apesar de atualmente não possuir concorrentes na área de atuação, pode, no futuro, em razão da aprovação do marco regulatório do setor de saneamento, por meio da Lei no 11.445/2007 e quando instituídas as entidades reguladoras, vir a enfrentar concorrência. Nos termos da legislação brasileira vigente, qualquer município, por razões de interesse público, pode terminar uma concessão, desde que exista lei autorizativa para tanto, antes da data do vencimento contratual. Nesse caso, o município deverá efetuar o integral pagamento dos valores, apurados em avaliação, de bens incorporados ao patrimônio da companhia, nos termos da concessão, previamente à transferência das atribuições e responsabilidades para o novo prestador ou concessionário.

\section{Processo de avaliação da companhia}

O primeiro passo para realizar a avaliação da companhia ocorreu com a formação do data room. Nessa etapa, todos os bancos que participaram da follow-on tiveram acesso a todas as informações da empresa por meio da intermediação do setor de Relações com Investidores (RI) da empresa. Nesse processo, foram discutidas e reorganizadas questões como: estatuto; documentação; revisão dos negócios da companhia; levantamento de necessidades.

Como a companhia já era listada na Comissão de Valores Mobiliários (CVM), muitas etapas do processo não precisaram ser feitas. Entretanto, foi necessário um trabalho árduo na parte de documentação, para o que o efetivo banco coordenador da oferta, Country Bank, contratou quatro diferentes escritórios de advocacia. Os advogados trabalham na elaboração dos prospectos da oferta e na reforma do estatuto e outros documentos, quando necessário. Essa é uma prática comum de mercado. Geralmente tem-se: um escritório para assessorar a companhia no Brasil, um escritório para assessorar a companhia no exterior, um escritório para assessorar os bancos no Brasil e um escritório para assessorar os bancos no exterior.

O passo seguinte desse processo ocorreu com a realização da estimação de preço da empresa. Esse passo foi prejudicado pelo fato de os bancos não terem feito a avaliação prévia da companhia. Como o Banco Dic contratou o Banco Bono por uma questão de contato não havia uma estimativa prévia detalhada da Sopape. Essa etapa é comum nesse mercado, em que os bancos podem competir pelo mandato de coordenação da oferta a partir do preço indicado privadamente como meta. Em substituição a um preço, o banco pode oferecer um intervalo preliminar do valor ou uma regra vinculada à tentativa de obter o maior preço em mercado possível para os vendedores.

Assim, todos os bancos participantes fizeram sua avaliação de maneira tardia para, posteriormente, reunirem-se e discutirem os seus resultados. Essa avaliação utilizou o fluxo de caixa descontado, considerando que o valor de uma empresa está diretamente relacionado aos montantes das épocas nas quais os fluxos de caixas operacionais estarão disponíveis para distribuição. Além desse, utilizaram o método de múltiplos, que apresenta uma abordagem simples de avaliação, comparando o valor de empresas semelhantes em relação a indicadores financeiros e operacionais com os valores relativos com os mesmos indicadores da empresa sob avaliação.

\section{Realização do road show e book building}

Até o início dos anos 1990, somente nos Estados Unidos e em outros mercados predominavam métodos de leilão para apreçamento de ofertas de ações. Entretanto, o cenário mudou com a onda das privatizações mundiais, que incentivou as empresas a procurarem recursos fora dos seus mercados locais. Nesse novo modelo globalizado, os grandes bancos de investimentos americanos incentivaram a utilização do book building como uma forma eficiente de minimizar o underpricing 
em emissões nas quais o grau de assimetria de informações pode ser alto. Os investidores poderiam revelar suas preferências com base em indicações de preço e demanda em seus lances.

No Brasil, a Instrução CVM no 400 regulamentou o uso do book building nas emissões de ações, tanto que, na onda dos IPOs de 2004 a 2007, todas as ofertas usaram o book building como procedimento para determinação do preço. O banco coordenador realiza o esforço de venda durante o road show, coleta intenções de investimento e dimensiona a demanda. No final, aloca as ações entre os investidores seguindo regras próprias, não explícitas, com pouca ou nenhuma transparência. Suspeita-se de que as regras envolvam o histórico de relacionamento entre o banco e o cliente, nível de preço e características de atuação do investidor em mercado.

Muitos criticam o book building por ser um método controverso, especialmente pelo poder discricionário concedido ao banco coordenador, tanto para escolha dos investidores quanto para fixação do preço da oferta. Entretanto, o book building apresenta muitos pontos relevantes que ajudam a extrair mais informações dos investidores. Quanto mais informações se extraem, melhor, em tese, é o processo de apreçamento. Além disso, o método controla e reduz os efeitos da maldição do vencedor (fenômeno no qual o ativo leiloado é arrematado pelo vencedor do leilão por preço superior ao seu valor intrínseco).

O Country Bank centralizou muito o processo de road show, pois possuía uma grande carteira de clientes internacionais. Porém, todos os bancos coordenadores da oferta participaram dessa parte do processo. Essa etapa durou cerca de uma semana, na qual foi estipulada uma agenda preliminar contendo os dias em que o presidente da Sopape, Sr. Carlos Eduardo Nicola, e o diretor financeiro da companhia, Felipe Copellete, deveriam estar nas reuniões com os investidores.

Durante o processo, o Country Bank construiu o livro de demandas com quantidades e preços indicados pelos investidores, uma vez que o processo utilizado de apreçamento foi o book building. Apenas o Country Bank e o Banco Bono tiveram acesso a esse livro. Os demais bancos contataram seus clientes e repassaram para os bancos coordenadores da oferta as intenções de investimentos e suas dimensões de demanda.

\section{Alocação das ações ofertadas}

O preço por ação foi fixado com base no resultado do procedimento de book building, conduzido pelo coordenador da oferta brasileira, Banco Bono, e pelo coordenador da oferta internacional, Country Bank, e acompanhado pelo agente estruturador, Banco Dic. A escolha desse critério para determinação do preço por ação foi justificada pelo fato de que o preço por ação não promoveria a diluição injustificada dos então acionistas da companhia e de que as ações seriam distribuídas por meio de oferta pública, em que o valor de mercado das ações foi aferido tendo como parâmetro (i) a cotação das ações ordinárias de emissão da companhia na BM\&FBovespa; e (ii) o resultado do procedimento de book building, que reflete o valor pelo qual os investidores institucionais apresentaram suas intenções de investimento no contexto da oferta global. Isso está em consonância com o disposto nos artigos 23, parágrafo $1^{\circ}$, e 44 da Instrução CVM 400, e de acordo com o artigo 170, parágrafo $1^{\circ}$, inciso III, da Lei das Sociedades por Ações.

Esse método de apreçamento também tende a beneficiar investidores de longo prazo em oposição aos chamados flippers, investidores que vendem grande parte das ações que recebem na oferta nos primeiros momentos de negociação no mercado secundário. Não costuma ser interessante para uma companhia ter ações alocadas para flippers, já que sua atuação contribui para volatilidade e desvalorização das ações. 
Após o processo de avaliação da Sopape, passou-se ao momento crítico de definição do preço da oferta. Como a empresa estava fazendo uma oferta follow-on, ou seja, já tinha ações negociadas na bolsa, a estipulação do preço seguiria critérios que observassem o comportamento do preço da ação nos últimos dias. Infelizmente, o período indicado para definição do valor está coincidindo com uma crise generalizada no mercado financeiro, em que praticamente todos os ativos se encontram com seus valores depreciados. O Anexo 2 exibe comparações do comportamento em mercado das ações da Sopape, de uma companhia com mesma atividade econômica que atua em outro município e de um índice representativo de mercado.

\section{Decisão}

A oferta em mercado de balcão será realizada nesta semana. A família Bonaparte, como detém a maior parte das ações, decide se continua no processo ou se adia a realização da oferta das ações. A família Suassuana continua pressionando para fazer oferta a despeito do nível de preço, já que necessita vender suas ações o mais rápido possível para não perder a oportunidade de investimento. Cancelar a oferta também pode ser interpretado negativamente pelo mercado. Investidores e analistas de mercado estão ansiosos pela oferta, e um cancelamento poderia sinalizar certa incapacidade dos gestores e dos bancos para conduzir o processo. Os bancos coordenadores estão em dúvida sobre qual seria o pior caminho: continuar com a oferta e, potencialmente, sinalizar para outras companhias que coordena ofertas com baixa qualidade no apreçamento ou cancelar a oferta e sinalizar para o mercado certa incompetência na condução do processo.

Você, como representante e defensor dos interesses da família Bonaparte, precisa decidir-se por um dos dois caminhos. A Sopape deve realizar a oferta neste momento? 
Anexo 1

Aberturas de capital no Brasil, volume e remuneração bruta e percentual e banco líder em ofertas selecionadas entre 2004 e 2007

\begin{tabular}{|c|c|c|c|c|c|c|}
\hline \multirow{3}{*}{$\begin{array}{l}\text { Companhia } \\
\text { BM\&F } \\
\text { PANAMERICANO }\end{array}$} & \multirow{2}{*}{\multicolumn{2}{|c|}{$\begin{array}{c}\text { Volume da Oferta } \\
\mathrm{R} \$ 5.983 .696 .920\end{array}$}} & \multirow{3}{*}{$\begin{array}{c}\text { Remuneração (\%) } \\
2.75 \% \\
4.00 \%\end{array}$} & \multicolumn{2}{|c|}{ Remuneração (R\$) } & \multirow{3}{*}{$\begin{array}{c}\text { Banco Líder } \\
\text { BBI } \\
\text { UBS }\end{array}$} \\
\hline & & & & $\mathrm{R} \$$ & 164.551 .665 & \\
\hline & $\mathrm{R} \$$ & 777.024 .000 & & $\mathrm{R} \$$ & 27.195 .840 & \\
\hline LAEP & $\mathrm{R} \$$ & 507.611 .108 & $5.00 \%$ & $\mathrm{R} \$$ & 25.380 .555 & UBS \\
\hline HELBOR & $\mathrm{R} \$$ & 267.327 .753 & $4.50 \%$ & $\mathrm{R} \$$ & 10.460 .651 & BBI \\
\hline BOVESPA & $\mathrm{R} \$$ & 6.625 .520 .875 & $2.00 \%$ & $\mathrm{R} \$$ & 132.510 .418 & CS \\
\hline AGRENCO & $\mathrm{R} \$$ & 716.151 .509 & $4.50 \%$ & $\mathrm{R} \$$ & 29.978 .435 & CS \\
\hline MARISA AS & $\mathrm{R} \$$ & 506.000 .000 & $3.00 \%$ & $\mathrm{R} \$$ & 15.180 .000 & CS \\
\hline TENDA & $\mathrm{R} \$$ & 693.450 .000 & $4.50 \%$ & $\mathrm{R} \$$ & 27.135 .000 & ITAU \\
\hline CBICBANCO & $\mathrm{R} \$$ & 821.526 .075 & $2.50 \%$ & $\mathrm{R} \$$ & 20.538 .152 & UBS \\
\hline SUL AMÉRICA & $\mathrm{R} \$$ & 775.000 .000 & $4.25 \%$ & $\mathrm{R} \$$ & 32.937 .500 & UNB \\
\hline HERING & $\mathrm{R} \$$ & 358.412 .450 & $5.00 \%$ & $\mathrm{R} \$$ & 15.583 .150 & ITAU \\
\hline TRIUNFO & $\mathrm{R} \$$ & 589.950 .000 & $6.00 \%$ & $\mathrm{R} \$$ & 30.780 .000 & CS \\
\hline KROTON & $\mathrm{R} \$$ & 478.773 .750 & $4.80 \%$ & $\mathrm{R} \$$ & 22.981 .140 & MS \\
\hline MINERVA & $\mathrm{R} \$$ & 510.600 .000 & $5.00 \%$ & $\mathrm{R} \$$ & 22.200 .000 & CS \\
\hline DROGASIL & $\mathrm{R} \$$ & 447.518 .810 & $4.00 \%$ & $\mathrm{R} \$$ & 15.707 .616 & UBS \\
\hline TEGMA & $\mathrm{R} \$$ & 603.980 .000 & $4.19 \%$ & $\mathrm{R} \$$ & 25.276 .563 & JP \\
\hline CRUZEIRO DO SUL & $\mathrm{R} \$$ & 644.197 .794 & $4.08 \%$ & $\mathrm{R} \$$ & 23.399 .463 & UBS \\
\hline LOGIN & $\mathrm{R} \$$ & 848.246 .654 & $3.00 \%$ & $\mathrm{R} \$$ & 22.344 .059 & UBS \\
\hline SLC AGRÍCOLA & $\mathrm{R} \$$ & 490.043 .750 & $4.50 \%$ & $\mathrm{R} \$$ & 22.051 .969 & CS \\
\hline INPAR & $\mathrm{R} \$$ & 756.000 .000 & $9.30 \%$ & $\mathrm{R} \$$ & 70.308 .000 & CS \\
\hline AGRA & $\mathrm{R} \$$ & 786.037 .500 & $3.50 \%$ & $\mathrm{R} \$$ & 27.511 .313 & CS \\
\hline BR MALLS & $\mathrm{R} \$$ & 696.070 .665 & $3.50 \%$ & $\mathrm{R} \$$ & 22.999 .153 & UBS \\
\hline EVEN & $\mathrm{R} \$$ & 460.000 .000 & $3.50 \%$ & $\mathrm{R} \$$ & 16.100 .000 & ITAU \\
\hline BANCO PINE & $\mathrm{R} \$$ & 594.766 .500 & $3.10 \%$ & $\mathrm{R} \$$ & 16.032 .836 & CS \\
\hline JBS & $\mathrm{R} \$$ & 1.840 .000 .000 & $4.00 \%$ & $\mathrm{R} \$$ & 64.670 .016 & JO \\
\hline GVT & $\mathrm{R} \$$ & 1.076 .400 .000 & $4.75 \%$ & $\mathrm{R} \$$ & 51.129 .000 & CS \\
\hline
\end{tabular}

Fonte: Elaboração dos autores usando dados coletados no site da CVM (www.cvm.gov.br) 
Anexo 2

Comportamento em mercado de ações da Sopape, de um concorrente e de um índice agregado de mercado.

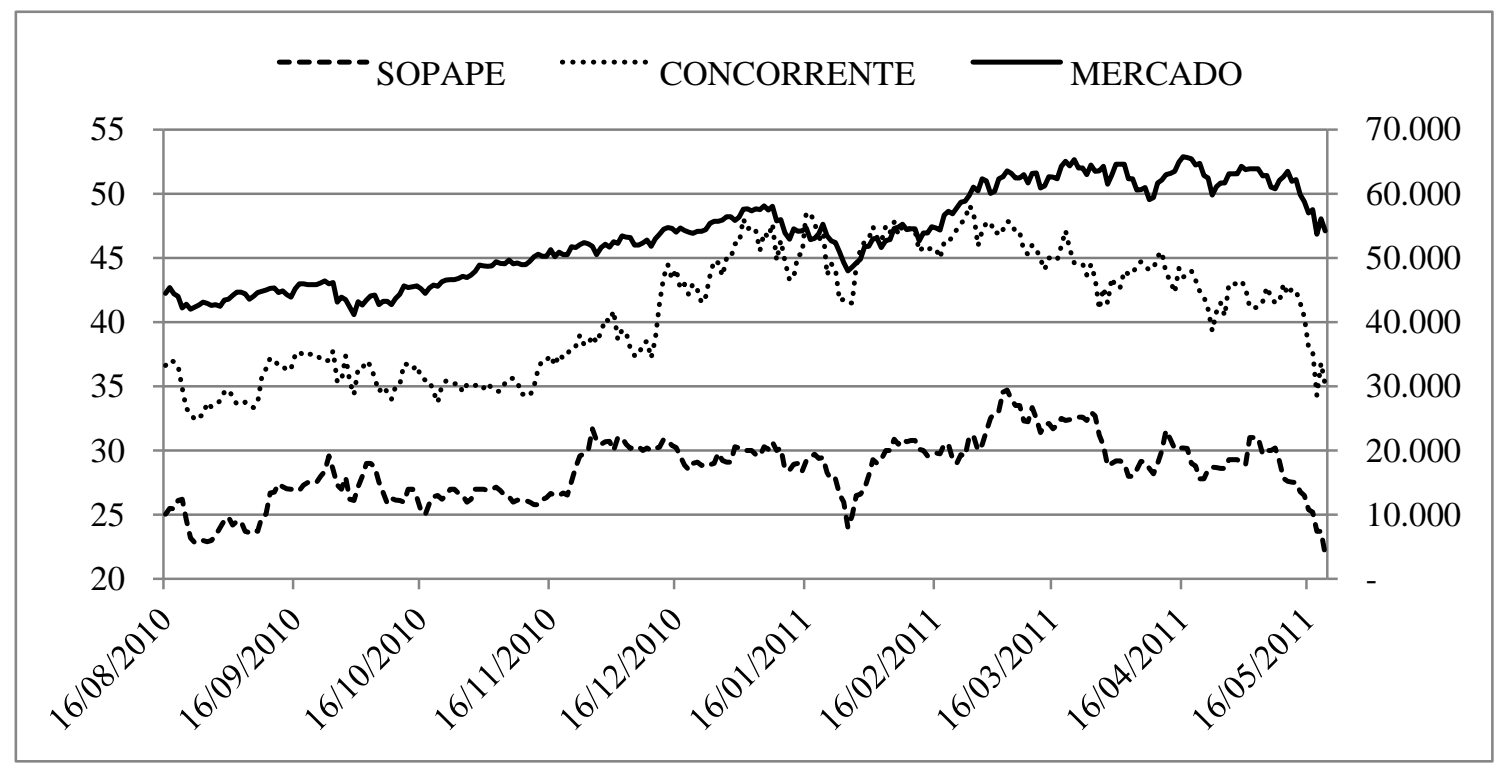

Obs.: O eixo vertical à esquerda refere-se às cotações diárias das ações da Sopape e da empresa concorrente. O eixo vertical à direita refere-se às cotações do índice de mercado. A última data no gráfico é a data de apreçamento da oferta da Sopape, onde está situada a decisão

Fonte: Elaboração dos autores usando dados coletados no terminal Bloomberg

\section{Comportamento em mercado de ações da Sopape, de um concorrente e de um índice agregado de mercado.}

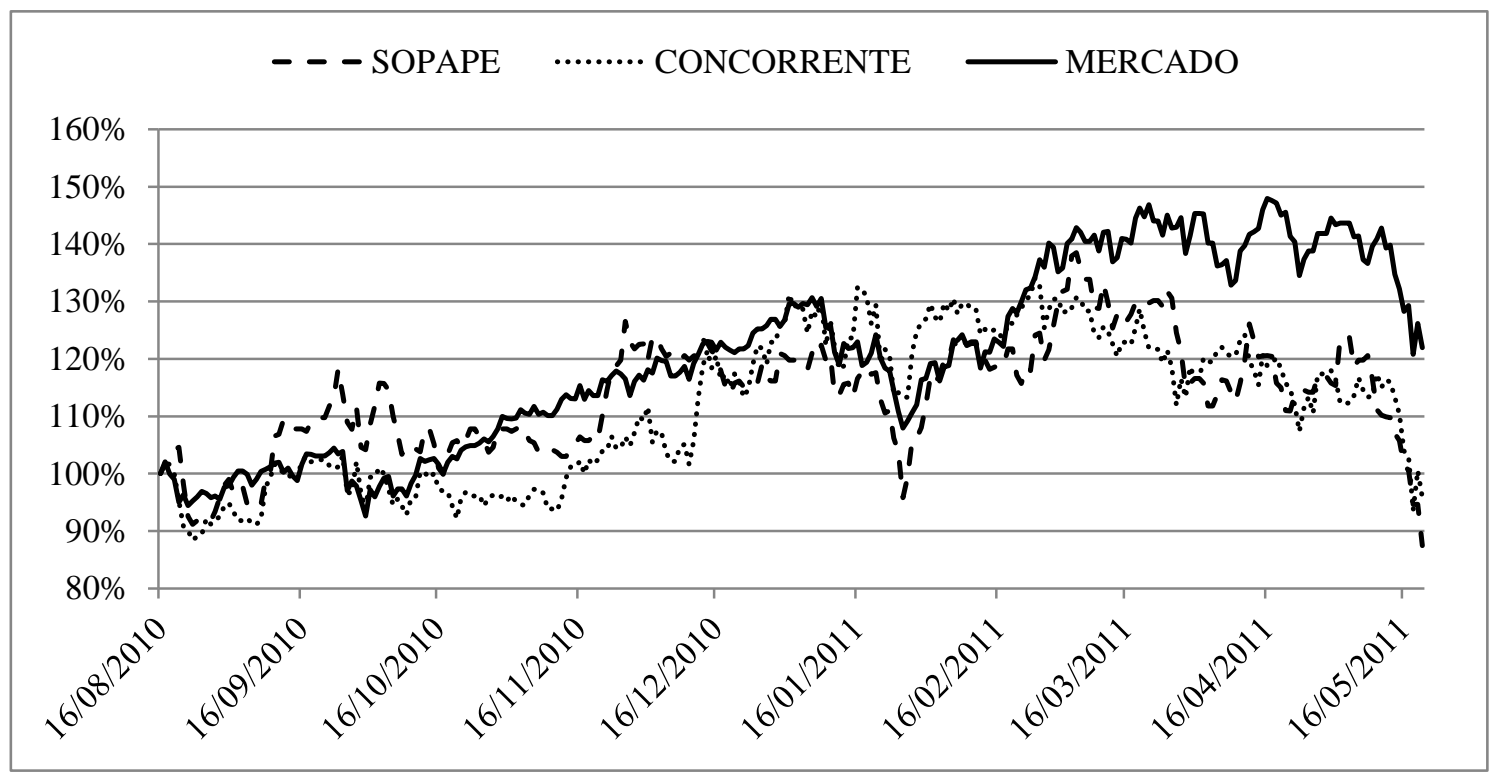

Obs.: O eixo vertical à esquerda refere-se a variações percentuais das cotações diárias das ações da Sopape, da empresa concorrente e do índice de mercado em relação a uma cotação fixada em 8.2010. A última data no gráfico é a data de apreçamento da oferta da Sopape, onde está situada a decisão

Fonte: Elaboração dos autores usando dados coletados no terminal Bloomberg 


\section{Anexo 3}

\section{Descrição de normas}

\section{Financial Holding Company (FHC)}

A FHC é uma autorização concedida para entidades financeiras envolvidas em uma ampla gama de atividades bancárias relacionadas, criada pela Lei Gramm-Leach-Bliley, de 1999. A autorização permite às instituições financeiras operar em todos os segmentos do mercado financeiro, qualificando subsidiárias para atuar como: bancos comerciais, bancos de investimentos, financeiras e companhias de seguro.

O FED é o órgão responsável por credenciar e supervisionar a situação financeira e as atividades das companhias financeiras. $\mathrm{O}$ objetivo é que o FED centralize a regulação de todas as empresas subsidiárias da FHC, mesmo aquelas consideradas não bancárias, impondo a elas uma mais rigorosa regulação prudencial, com maiores exigências de capital e uma supervisão mais consolidada. O interesse é obrigar essas firmas a internalizar os possíveis custos impostos à sociedade no caso de uma falência.

\section{Regra 144A e Reg S}

Editada pela SEC, a Regra 144A permite a colocação de valores mobiliários a investidores institucionais qualificados, assim considerados por possuírem um alto nível de sofisticação e maior tolerância ao risco, sem necessidade de realização de uma oferta pública registrada nos termos do Securities Act. Apesar de a colocação sob a Regra 144A não possibilitar ao emissor o acesso a um amplo mercado, permite uma distribuição mais extensa, podendo ser utilizada para captar mais recursos que uma colocação privada tradicional.

A vantagem trazida pela 144A consiste, em linhas gerais, em uma isenção dos requisitos de registro estabelecidos na Seção 5 do Securities Act. Seu objetivo é atrair companhias emissoras estrangeiras desiludidas em face dos limites das emissões privadas tradicionais e pelos rigorosos requisitos de registro e transparência (disclosure) de uma oferta pública.

A 144A isenta de registro a revenda de valores mobiliários, desde que as principais condições a seguir sejam cumpridas: (i) ofertas somente podem ser feitas aos investidores institucionais qualificados ou àqueles que o ofertante acredita, de modo razoável, tratar-se de qualificado; (ii) os compradores devem ser informados de que a compra não é registrada sob o Securities Act; (iii) os valores mobiliários ofertados não podem ser da mesma classe (ou equivalentes, para fins de negociação) aos valores mobiliários do respectivo emissor negociados em bolsas de valores dos Estados Unidos ou na Nasdaq (iv); os compradores devem estar aptos a obter, de maneira contínua (em última instância, pelo emissor), as demonstrações financeiras e outras informações recentes relativas ao negócio. Do ponto de vista prático, companhias cujos valores mobiliários são negociados no país de origem frequentemente satisfazem tal requisito por meio de uma isenção que lhes permite disponibilizar para investidores residentes nos Estados Unidos os relatórios periódicos, bem como outras informações fornecidas de tempos em tempos ao público, registrados nas comissões de valores mobiliários de seus próprios países. A Reg S tem efeitos semelhantes aos da 144A, mas é aplicada a não residentes nos Estados Unidos.

Em contrapartida, sob a Regra 144A, em razão de os valores mobiliários somente poderem ser oferecidos a investidores qualificados, e diante das restrições em questões relativas a propaganda e publicidade, a oferta tenderá a ser menor, podendo ocasionar impactos na oferta secundária. E, em 
razão das restrições na revenda dos valores mobiliários, é possível, também, que o preço não alcance o mesmo nível que atingiria em uma oferta pública.

\section{Lei Sarbanes-Oxley (SOX)}

A partir do ano 2000, vários órgãos reguladores descobriram e revelaram muitos casos de más práticas empresariais, decorrentes de dois tipos principais de problema: fraude em relatórios financeiros e outros comunicados ao público; e não divulgação de conflitos de interesses entre empresas e seus analistas, auditores e advogados, e entre diretores, executivos e acionistas. Em resposta a essas fraudes e conflitos de interesses, o Congresso dos Estados Unidos aprovou, em julho de 2002, a Lei Sarbanes-Oxley (SOX).

A SOX tem por objetivo eliminar conflitos de interesse em relação à divulgação de dados pelas empresas. Aplica-se aos relatórios financeiros das empresas e às relações entre sociedades por ações, analistas, auditores, advogados, membros do conselho, diretores executivos e acionistas. 